\title{
Sex Steroids Influence Pancreatic Islet Hypertrophy and Subsequent Autoimmune Infiltration in Nonobese Diabetic (NOD) and NODscid Mice
}

\author{
Judith G. M. Rosmalen, Marieke J. G. Pigmans, Rogier Kersseboom, \\ Hemmo A. Drexhage, Pieter J. M. Leenen, and Françoise Homo-Delarche \\ Department of Immunology (JGMR, MJGP, RK, HAD, PJML), Erasmus University, Rotterdam, the Netherlands; and \\ CNRS UMR 8603 (FH-D), Université Paris V, Hôpital Necker, Paris, France
}

SUMMARY: Female nonobese diabetic (NOD) mice more frequently develop autoimmune diabetes than NOD males. Orchidectomy of the latter aggravates insulitis and diabetes. Because clear differences in immune function have not been observed between prediabetic females and males, before or after castration, we hypothesized that sex-related differences in diabetes incidence are related to target organ-specific actions of sex steroids. Previously, we showed that prediabetic NOD females develop hyperinsulinemia and subsequently mega-islets. Infiltration of the first inflammatory leukocytes is predominantly associated with these mega-islets. Here, we determined the relationship between sex hormones, mega-islet formation, and infiltrating cells in NOD and nonobese diabetic/severe combined immune-deficient (NODscid) mice. Mega-islet formation was reduced in NOD males compared with NOD females, and orchidectomy increased it, indicating a relationship between androgen levels and mega-islet formation. Moreover, enhanced mega-islet formation in castrated NOD males was associated with increased numbers of infiltrating leukocytes. Castrated NODscid males also exhibited increased mega-islet formation and dendritic cell infiltration, indicating that lymphocytes are not required for castration-induced effects. In conclusion, we show that androgens influence pancreatic islets and autoimmune infiltration in NOD and NODscid mice. This suggests that the gender difference in diabetes incidence in NOD mice is related to target organ-specific androgen effects. (Lab Invest 2001, 81:231-239).

$T$ he sexual dimorphism of autoimmune diseases-females have a higher incidence than males-is well known in both humans and animal models (Ansar Ahmed et al, 1985; Beeson, 1994; Homo-Delarche et al, 1991; Wilder, 1995). This difference is generally assumed to be caused by the effects of sex steroids on the immune response, particularly the immunosuppressive effects of androgens (Grossman, 1984; Homo-Delarche and Durant, 1994; HomoDelarche et al, 1991; Wilder, 1995).

Also in the nonobese diabetic (NOD) mouse model of type 1 diabetes, females become diabetic earlier and in higher frequency than males. Castration of males leads to an incidence comparable to that observed in females, whereas treatment with androgens prevents the development of diabetes in female NOD mice (Fitzpatrick et al, 1991; Fox, 1992). It is generally assumed that the autoimmune process in NOD females and castrated males progresses because of the absence of immunosuppressive androgens. However,

Received November 21, 2000

This work was supported by grants from the Diabetes Fonds Nederland, CNRS, Université de Paris V, Alfediam (associated with Lilly Laboratories), NWO-INSERM, and BIOMED (Betimmune).

Address reprint requests to: Dr. F. Homo-Delarche, CNRS UMR 8603, Hôpital Necker, 161 rue de Sévres, 75015 Paris, France. E-mail: fhomodel@wanadoo.fr data comparing various immunological parameters between NOD females and males, and between castrated and control animals of both sexes, have not given conclusive evidence to support such a view. Splenic T-cell proliferation, interleukin-2 production, and antibody production against sheep red blood cells do not reveal any spontaneous sex difference or any effect of castration, whereas leukocyte phenotype analysis shows only minor differences (Fitzpatrick et al, 1991). In addition, autoimmune inflammatory infiltration is not always predominant in females. Although a NOD female preponderance exists for the development of insulitis and sialoadenitis (Fitzpatrick et al, 1991; Goillot et al, 1991), dacryoadenitis is preferentially found in NOD males (Hunger et al, 1998). Taken together, these observations in NOD mice bring into question the general view that sex steroid effects on the immune system explain the observed gender difference in diabetes incidence. Alternatively, sex hormones may directly affect the target organ and thus influence the susceptibility for autoimmune attack.

In the NOD pancreas, the first sign of autoimmunity is an early accumulation of macrophages $(M \phi)$ and dendritic cells (DC) around the islets of Langerhans (peri-insulitis) (Jansen et al, 1994; Rosmalen et al, $2000 \mathrm{~b})$. These cells are assumed to function as antigen-presenting cells (APC). Subsequently, numerous $T$ and $B$ lymphocytes are recruited to the site and 
the progressive insulitis leads to the destruction of the insulin-producing $\beta$ cells located in the core of the islet of Langerhans. In the nonobese diabetic/severe combined immune-deficient (NODscid) mouse, an early peri-islet APC accumulation also takes place, but to a lesser extent (Dahlen et al, 1998; Rosmalen et al, 2000a). Because of the lack of functional lymphocytes, however, neither lymphocyte insulitis nor diabetes develops in these mice (Prochazka et al, 1992). With age, both NOD and NODscid females exhibit increased numbers of large-sized islets ("megaislets") (Jansen et al, 1996; Rosmalen et al, 2000a). The importance of these mega-islets for diabetes development is indicated by the observation that the early-infiltrating APC are predominantly situated next to these mega-islets in both strains (Rosmalen et al, 2000a). This is particularly the case for CD11c ${ }^{+}$dendritic cells (DC).

The causes of mega-islet development are not known. Islet hypertrophy occurs consecutively to endocrine abnormalities, suggesting a role for these abnormalities in mega-islet development. More specifically, a transient $\beta$ cell hyperactivity is observed in NOD mice, particularly females, that is closely associated in time with the emergence of APC infiltration (Amrani et al, 1998; Homo-Delarche, 1997). Interestingly, an aberrant sexual dimorphism in insulin response to a glucose load exists in NOD mice: females produce, as early as 6 weeks of age, higher insulin levels than males (Homo-Delarche, 1997). This glucose response pattern is opposite to the one found in normal rodents (Homo-Delarche, 1997). Moreover, insulitis progresses more rapidly in NOD females than in males, possibly as a consequence of this $\beta$ cell hyperactivity (Amrani et al, 1998; Homo-Delarche, 1997; Homo-Delarche and Boitard, 1996). Thus, functional endocrine abnormalities in NOD mice precede the formation of mega-islets and subsequent autoimmune infiltration. Moreover, these abnormalities seem to be especially marked in diabetes-prone NOD females.

We hypothesized that the sensitivity to autoimmune attack as observed in NOD females was related to sex steroid effects on the target organ instead of on the immune system. Therefore, we have studied the effect of castration on the islet of Langerhans by measuring early mega-islet development, APC infiltration, and the relationship between these two parameters. By using both NOD and NODscid mice, we determined the contribution of lymphocytes to islet abnormalities developing upon castration.

\section{Results}

\section{Gender Bias in Mega-Islet Formation in NOD and NODscid Mice}

Previous studies showed early hypertrophy of pancreatic islets, leading to mega-islet formation in NOD and NODscid female mice (Jansen et al, 1996; Rosmalen et al, 2000a). Figure 1 shows an example of a megaislet (Fig. 1A) compared with conventional islets (Fig.
1B). To assess a possible sexual dimorphism in megaislet formation, we measured islet size in NOD and NODscid mice of both sexes at 5, 10, and 15 weeks of age. Mega-islets were defined as islets with an area of more than 10,000 pixels at a magnification of $\times 100$. Five-week-old females and males of both strains had comparable percentages of mega-islets (Fig. 2). At 10 weeks of age, however, significant differences in the percentages of mega-islets were observed between females and males regardless of the strain. NOD and NODscid females had higher percentages of megaislets than NOD and NODscid males $p<0.05$ for NOD females vs NOD males; $p<0.05$ for NODscid females vs NODscid males). However, after the appearance of this sexual dimorphism in mega-islet development in both NOD and NODscid mice, a strain difference developed, as observed at 15 weeks of age. Significantly higher percentages of mega-islets were observed in NOD females and males compared with sex-matched NODscid mice $p<0.05$ for NOD females vs NODscid females; $p=0.05$ for NOD males vs NODscid males). This suggests that lymphocytes play a role in later phases of mega-islet development in NOD mice. These data also show that the initial phases of mega-islet development are influenced by sex steroids.

\section{Gender Bias in $\mathrm{CD}_{11 C^{+}}$DC Infiltration in NOD Mice}

To assess whether the gender bias in mega-islet formation was associated with differences in early insulitis in male and female NOD mice, we measured

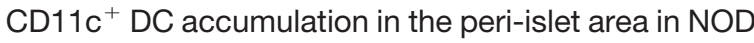
males and females at 5 weeks of age. The percentage of islets with $\mathrm{CD} 11 \mathrm{c}^{+} \mathrm{DC}$ in the peri-islet area was comparable between NOD males and NOD females: in both males and females, a similar fraction of the islets had $\mathrm{CD}_{11 \mathrm{C}^{+}} \mathrm{DC}$ in the peri-islet area at this age. However, the percentage of the area occupied by $\mathrm{CD}_{11 \mathrm{C}^{+}} \mathrm{DC}$ in these infiltrated islets differed significantly: $3.8 \%$ versus $1.0 \%$ of the peri-islet surface area was occupied by DC in the infiltrated islets in females compared with males $(p<0.05)$. Thus, female NOD mice had a higher density of $\mathrm{CD}_{11 c^{+}} \mathrm{DC}$ in the peri-islet area of infiltrated islets than male NOD mice.

\section{Effect of Castration on Mega-Islet Formation in NOD and NOD scid Males and on Diabetes Incidence in NOD Males}

As shown in Figure 3, orchidectomy of NOD and NODscid mice at 4 weeks of age significantly increased the fraction of mega-islets at 10 weeks of age $(p<0.001$ for NOD males; $p<0.05$ for NODscid males). This increase is especially marked in NOD males, leading to a significant difference between orchidectomized NOD and NODscid males $(p<$ 0.001). We also confirmed previous findings that orchidectomy at 4 weeks of age significantly increased diabetes prevalence in NOD males (data not shown). 


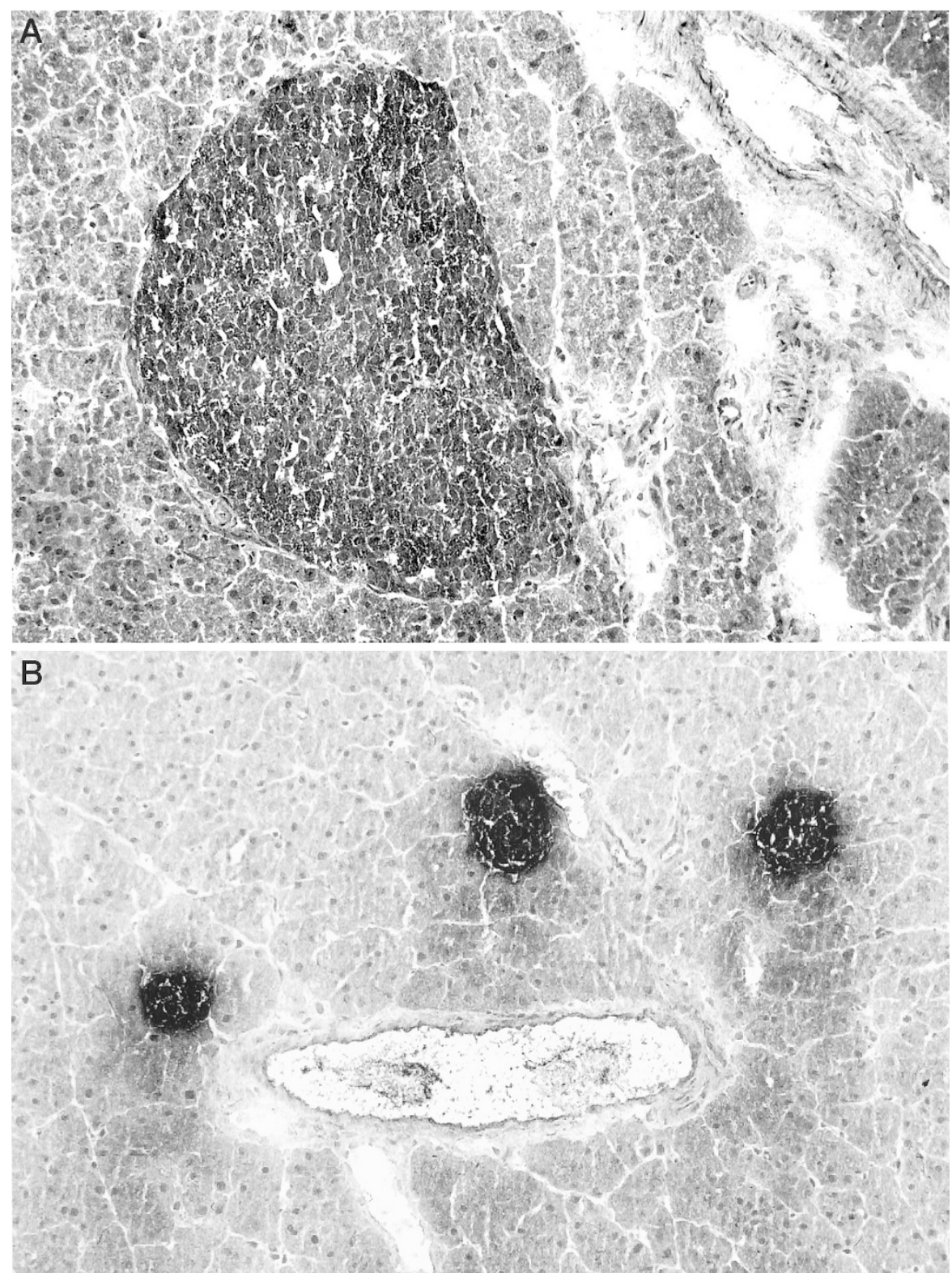

Figure 1.

Example of a mega-islet (orchidectomized NOD male, 10 weeks old) (A) compared with conventional islets (sham-operated NOD male, 10 weeks old) (B). Original magnification: $\times 64$. Note the weak staining for insulin in the mega-islet compared with the staining in the conventional islets, a difference that is regularly observed.

\section{Effect of Castration on DC Infiltration around and/or into Islets of NOD and NOD scid Males}

Because CD11C ${ }^{+}$DC accumulate around, as well as within, the islet when insulitis is progressing (Fig. 4), we measured infiltration in the peri-islet area and in the islet itself at 10 weeks of age. Figure 5 shows that orchidectomy in NOD mice enhanced the accumulation of $\mathrm{CD}_{11 \mathrm{c}^{+}} \mathrm{DC}$ in both the islet itself $(4.4 \% \mathrm{vs}$ $1.1 \%$ of the islet surface area was occupied by DC in the orchidectomy vs the sham-operated group, $p<$ $0.0001)$ and in the peri-islet area $(19.2 \%$ vs $6.7 \%$ for the orchidectomy vs the sham-operated group, $p<$ 0.0001). In NODscid mice, the accumulation of $\mathrm{CD}_{11 \mathrm{C}^{+}} \mathrm{DC}$ was also significantly enhanced in the peri-islet area after orchidectomy $(2.7 \%$ vs $1.4 \%$ for the orchidectomy vs the sham-operated group, $p<$
$0.001)$, but in the islet itself, the difference did not reach statistical significance $(0.38 \%$ vs $0.25 \%$ for the orchidectomy vs the sham-operated group).

NOD and NODscid mice differed significantly with regard to peri-islet or intra-islet CD11 $\mathrm{C}^{+} \mathrm{DC}$ infiltration (Fig. 5). In sham-operated NOD males, CD11c ${ }^{+}$ DC infiltration was more extensive than in NODscid males, both in the islet itself $(1.1 \%$ vs $0.25 \%$ for NOD vs NODscid, $p=0.0001)$ and in the peri-islet area $(6.7 \%$ vs $1.4 \%, p<0.001)$. After orchidectomy, this difference increased both in the islet itself $(4.4 \%$ vs $0.38 \%, p<0.0001)$ and in the peri-islet area (19.2\% vs $2.7 \%, p<0.0001)$. This suggests that lymphocytes are likely to play a role in the extent of peri- and intra-islet DC infiltration in the NOD mouse. 


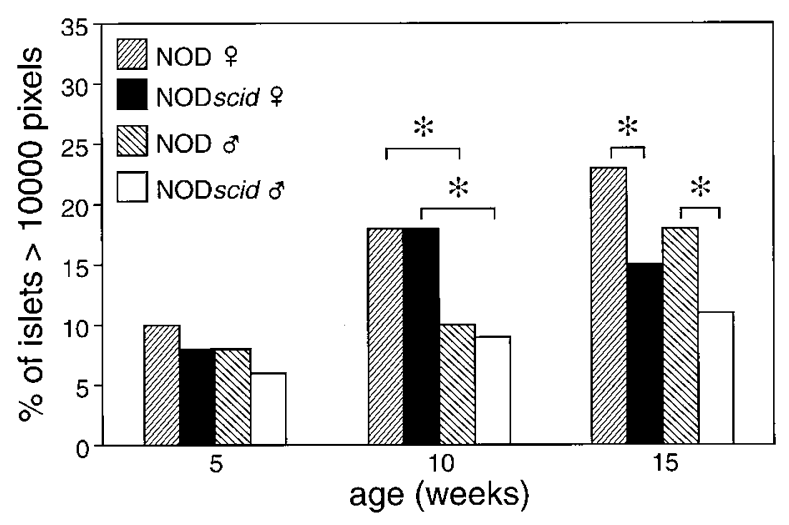

Figure 2.

Development of mega-islets as a function of age in NOD and NODscid females and males. Results are percentages of the total number of islets from five mice. Note a significant difference between males and females at 10 weeks of age and a significant difference between NOD and NODscid mice, regardless of the sex, at 15 weeks of age.

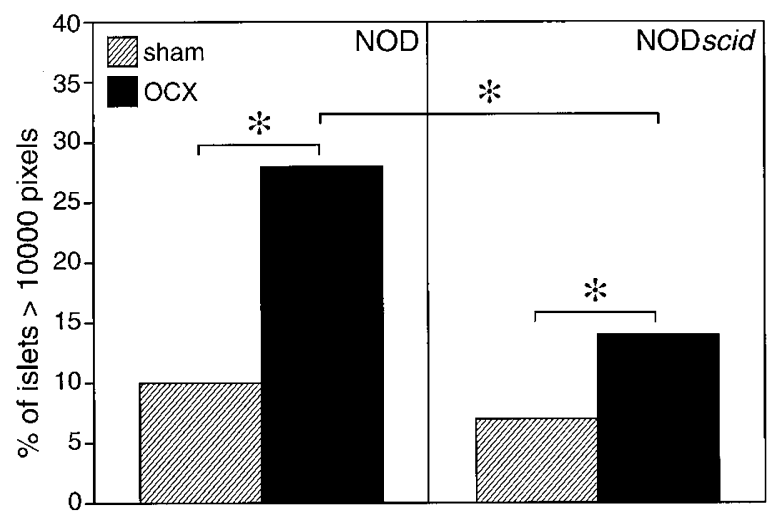

Figure 3.

Presence of mega-islets in orchidectomized and sham-operated 10-week-old NOD and NODscid males. Results are percentages of the total number of islets from 6 to 8 mice/age group. Orchidectomy results in a rise in the percentage of mega-islets. Moreover, this effect is significantly higher in NOD compared with NODscid males.

\section{Effect of Castration on Islet-Related Lymphocyte Infiltration in NOD Males}

Figure 6 shows that orchidectomy of 4-week-old NOD mice increased the lymphocytic infiltration, as measured at 10 weeks of age. Indeed, the median size of the lymphocyte infiltrate was 856 pixels for shamoperated NOD males and 2398 pixels for orchidectomized NOD. However, this difference tended only toward significance $(p=0.088)$. As expected, NODscid mice did not exhibit any lymphocyte infiltration.

\section{Discussion}

In the NOD mouse model of type 1 diabetes, females are more prone to diabetes development than males, despite the absence of clear differences in peripheral immune function between the sexes (Fitzpatrick et al, 1991). Similarly, castrated males show an enhanced diabetes incidence without obvious changes in peripheral immune function (Fitzpatrick et al, 1991). Therefore, we hypothesized that a target organ- specific effect of sex steroids is operative in diabetes development. This study shows that orchidectomy induces early islet abnormalities in male NOD mice, indicated by the increase in mega-islet formation in castrated animals. Simultaneously, orchidectomy enhances early APC infiltration in NOD and NODscid mice. The effect of orchidectomy on both mega-islet formation and APC infiltration is stronger in NOD than in NODscid mice, indicating that lymphocytes enhance the effect of androgen deprivation.

The relationship between sex steroids, mega-islet formation, and leukocyte infiltration can be explained in different ways. On the one hand, the effects of orchidectomy on the development of early islet abnormalities in male NOD mice may be achieved via a direct influence of sex steroids on islet cells and/or glucose homeostasis. On the other hand, sex steroids may affect the function of leukocytes that accumulate around and in the islets, and thereby cause islet abnormalities. The data presented here and those from the literature suggest that both mechanisms may be at work.

There are several indications that the islet itself can respond to sex hormones. Functional studies suggest that sex steroids might directly and/or indirectly influence islet function in normal animals. There is a sexual dimorphism in glucose homeostasis in normal rodents, with males showing higher nonfasting basal glycemia and insulinemia than females (HomoDelarche, 1997; Lavine et al, 1971). This difference is related to the opposite effects of androgens and estrogens on the insulin sensitivity of cells: androgens lower insulin sensitivity, whereas estrogens increase it (Kava et al, 1989; Leiter, 1988, 1989). Accordingly, partial pancreatectomy-induced diabetes in normal rodents is more frequent in males than in females, and its effect is reversed in each sex by castration (Houssay, 1951). The administration of exogenous androgens is likely to prevent the effects of castration on glucose homeostasis because in the multiple-dose streptozotocin diabetes model it has been shown that testosterone administered to control females or orchidectomized males resulted in an increase in glucose response to levels comparable to those in control males (Rossini et al, 1978). Finally, estrogen administration in rodents and orchidectomy in various species have been reported to induce $\beta$ cell hyperplasia and/or islet hypertrophy (Bailey and Ahmed-Sorour, 1980; Basabe et al, 1969; Renauld et al, 1980). Thus, our finding in NOD mice that orchidectomy led to an increased percentage of mega-islets in prediabetic NOD males (before any noteworthy lymphocyte infiltration) and in NODscid males is fully in line with the earlier observations in other strains and species that sex steroids influence $\beta$ cell function. Do sex steroids act directly at the $\beta$ cell level through specific receptors? Estrogen and progesterone receptors are indeed present in $\beta$ cells (Doglioni et al, 1990; Lenzen and Bailey, 1984; Tesone et al, 1979; Winborn et al, 1983). However, to the best of our knowledge, androgen receptors have not been shown in $\beta$ cells. In addition, we ourselves were unable to detect the presence of 


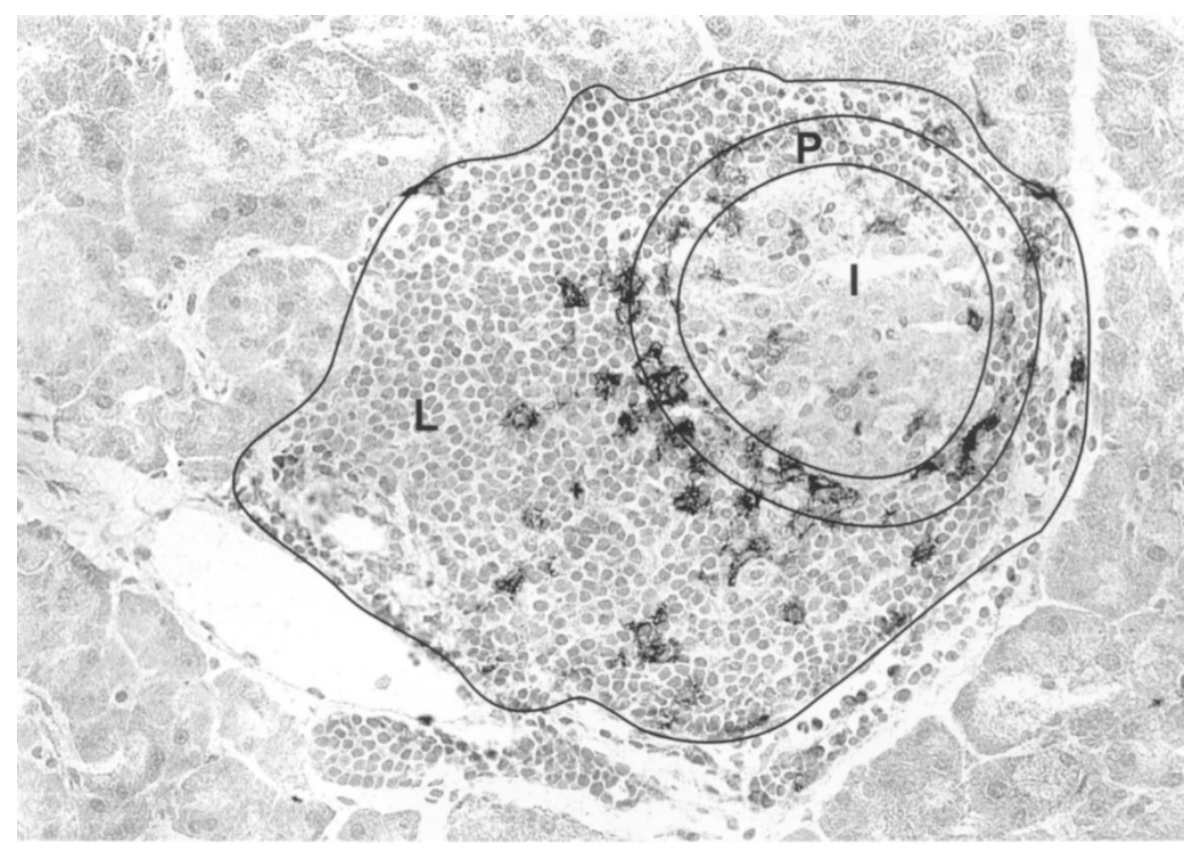

Figure 4.

The location of $\mathrm{CD}_{11 \mathrm{C}^{+}} \mathrm{DC}$ (black staining) and lymphocytes in islet infiltrates (NOD female, 10 weeks old). I, islet; P, peri-islet area; L, lymphocyte infiltrate. Original magnification: $\times 64$.

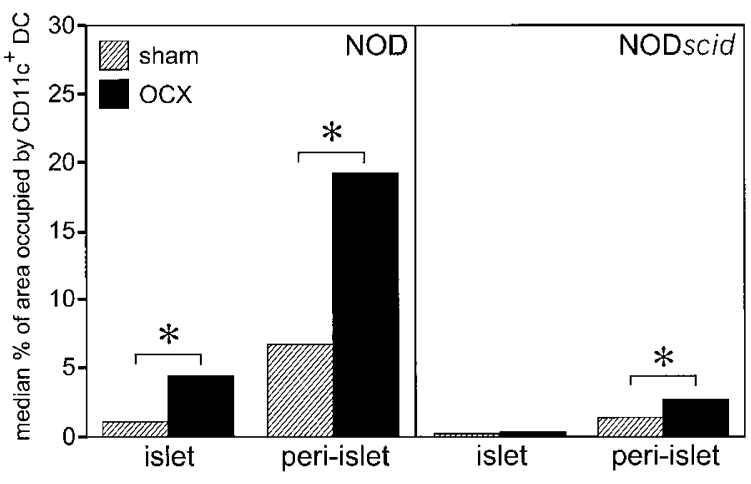

Figure 5.

$\mathrm{CD}_{11 \mathrm{C}^{+}} \mathrm{DC}$ infiltration in orchidectomized and sham-operated 10-week-old NOD and NODscid males. Infiltrating DC are distinguished according to their location: with the islets or in the peri-islet inflammatory infiltrate. The number of infiltrating cells is expressed relative to the islet or peri-islet surface area (see "Materials and Methods"). Note that orchidectomy of NOD and NODscid males leads to an enhanced accumulation of $C D 11 c^{+} \mathrm{DC}$ around the islets. In NOD mice, orchidectomy also leads to an enhanced infiltration of $C D 11 c^{+} D C$ into the islets. As expected for this age, peri-islet infiltration is significantly

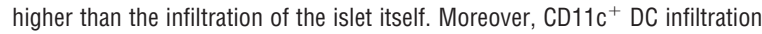
in NOD males is significantly higher compared with that in NODscid males.

these receptors in $\beta$ cells (unpublished observation). These data make a direct effect of androgens at the $\beta$-cell level unlikely.

If indeed $\beta$ cells lack androgen receptors, is there an alternative explanation for the observed gender difference in diabetes incidence and the effect of orchidectomy in NOD mice? Sex steroids also have recognized effects on leukocyte function. It could be argued that sex steroids induce prediabetic islet abnormalities via an effect on leukocytes, either lymphocytes or APC, that accumulate around the islets.
We show here that orchidectomy affects mega-islet formation and APC infiltration in lymphocyte-deficient NODscid mice. This indicates that at least part of the sex-steroid effect, if achieved indirectly, can be mediated via nonlymphoid cells. APC are likely candidates as mediators of sex-steroid effects. In general, a close physical and functional interaction between the endocrine system and APC has been observed for virtually all endocrine organs (Hoek et al, 1997; Simons et al, 1998). In the thyroid, pituitary, and the gonads, DC and macrophages play an important role in the regulation of hormone secretion (Hoek et al, 1997; Simons et al, 1998). One study also suggests the possible effects of APC on islets and a role for sex steroids in this interaction. In mice that express interferon- $\gamma$ as a transgene in their $\beta$ cells, interferon- $\gamma$-stimulated duct cell proliferation is stronger in females than in males. However, if the pancreatic influx of $M \phi$ that occurs in these mice is prevented, the proliferation in males is increased up to the level found in females. Hence, interferon- $\gamma$ stimulation of duct cell proliferation is mediated in part through the $\mathrm{M} \phi$, which inhibits such growth in males (Gu et al, 1995). Androgens thus influence the function of pancreatic $\mathrm{M} \phi$, thereby inhibiting islet precursor cell proliferation. Consequently, the administration of exogenous androgens in NOD females and orchidectomized NOD males may well affect the pancreatic APC and thereby inhibit the observed islet hypertrophy.

Therefore, APC appear to be important communicators in the interactions between the endocrine and the immune system. How could sex steroids influence the interactions between APC and islet cells? Sex steroids are known to modulate cytokine production by leukocytes, in particular by mononuclear phago- 


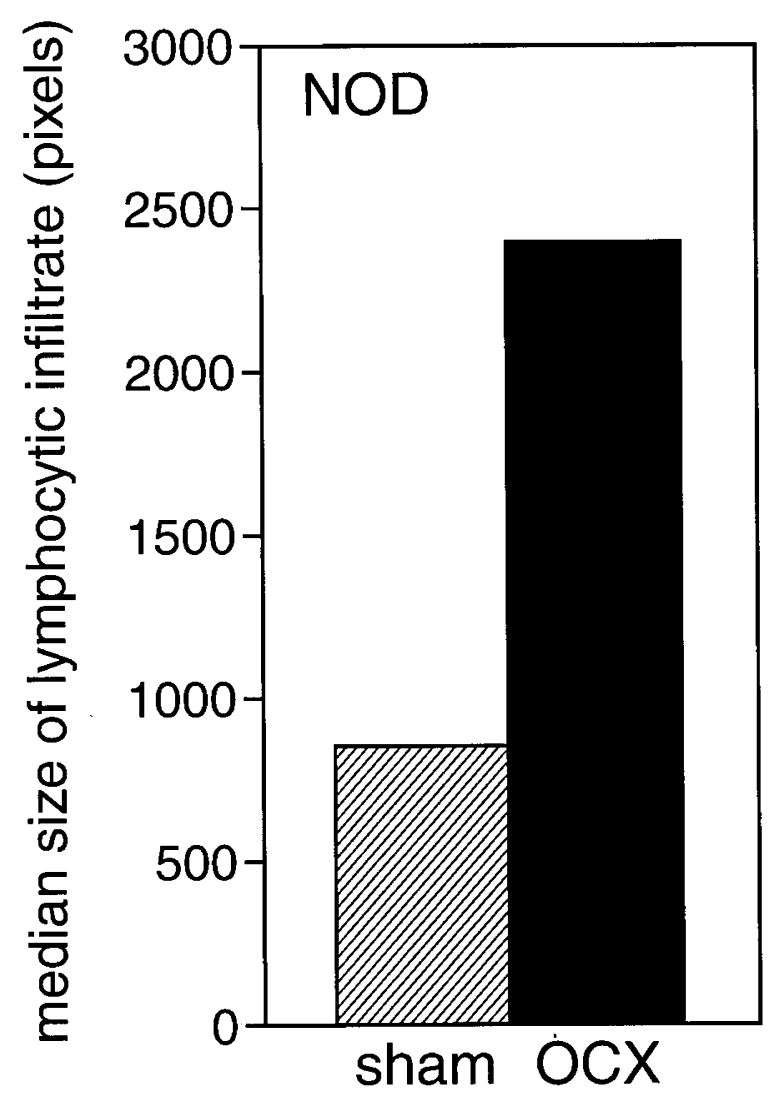

Figure 6.

Development of lymphocyte infiltration in orchidectomized and sham-operated 10-week-old NOD males. Orchidectomy tended to increase the size of the lymphocyte infiltrate $(p=0.088)$

cytes (Homo-Delarche and Durant, 1994). Furthermore, APC are able to convert prohormones to active androgens (Hennebold and Daynes, 1994). Taken together, these notions support the view that sex steroids influence APC function and thus might via these cells also influence the islet cells.

The effects of orchidectomy on mega-islet formation are stronger in NOD males than in NODscid males, however. This suggests that lymphocytes also contribute to mega-islet formation in NOD mice. A direct lymphocyte-mediated effect of changes in androgen levels, however, is unlikely because mature lymphocytes lack androgen receptors (Homo-Delarche and Durant, 1994). How then can the reduced effect of castration on mega-islet formation in NODscid mice compared to NOD mice be explained? Androgens might act indirectly on lymphocytes by influencing products secreted by other cells present in the islet environment (Pavlovic et al, 1999). Moreover, circulating estrogens, which persist in NOD males after castration, may have direct and similar immunostimulatory effects on lymphocytes from NOD females and castrated males that are not counterbalanced by the presence of androgens (Ansar Ahmed et al, 1985; Grossman, 1984; Homo-Delarche and Durant, 1994). Also, a role for infiltrating APC in this process can be envisaged. NODscid have a reduced DC infiltration compared with NOD mice as shown for males in this study and in Rosmalen et al (2000a) for females. Therefore, the difference between NOD and NODscid mice in mega-islet formation after orchidectomy could be explained via effects on different numbers of infiltrating DC.

In conclusion, both leukocytes and islet cells themselves appear to play roles in the formation of megaislets after castration. In this experimental setting as well as in spontaneous disease, $\beta$-cell hyperactivity and islet hypertrophy might be crucial in the development of diabetes. Hyperactive islets are known to express elevated levels of cell-adhesion ligands, major histocompatibility complex (MHC) molecules, and autoantigens, which may enhance the $\beta$-cell sensitivity to the cytotoxic effects of cytokines (Homo-Delarche and Boitard, 1996). We have previously demonstrated that prophylactic insulin treatment, which prevents insulitis and diabetes incidence, decreases mega-islet formation (Jansen et al, 1996; Rosmalen et al, 2000a). Here we show that orchidectomy is associated with an increase of both mega-islet formation and the incidence of diabetes in NOD mice. Moreover, orchidectomy enhances the early accumulation of $\mathrm{CD} 11 \mathrm{c}^{+} \mathrm{DC}$ around and in the islets of NOD mice and NODscid mice concomitantly with mega-islet formation. Together, these studies support the view that megaislets are closely associated with, and possibly functionally involved in, the development of insulitis and, subsequently, diabetes in NOD mice. Because NODscid mice lack functional lymphocytes, the stage of destructive insulitis is not reached in this strain.

In this report we highlight the notion that sex steroids are important factors in the complex interrelationship between the islets of Langerhans and early infiltrating leukocytes in mice with the NOD genetic background. Sex steroids influence early prediabetic morphological islet abnormalities, and orchidectomy increases mega-islet formation and associated APC infiltration. This effect is enhanced by the presence of functional lymphocytes. In addition, an effect of androgens on islet cells, either directly or indirectly via infiltrating APC, provides an explanation for the observed gender difference in diabetes incidence in NOD mice.

\section{Materials and Methods}

\section{NOD Colony, Diabetes Incidence, and Orchidectomy}

NOD and NODscid mice were bred under specific pathogen-free conditions at the facilities of the Hôpital Necker, Paris, France. The animal facilities and care followed the principles of laboratory animal care and the norms stipulated by the European Community. Mice were fed standard pellets and water ad libitum and were maintained at $22^{\circ} \mathrm{C}$ on a 12-hour light-dark cycle. The incidence of diabetes in the NOD colony was $80 \%$ for females and $40 \%$ for males by 200 days of age.

NOD and NODscid males were divided into two experimental groups. The first group underwent either orchidectomy under Avertin anesthesia at 4 weeks of 
age. The second group underwent a sham operation to exclude the nonspecific effects of the operation itself. Mice were routinely checked for success of the orchidectomy. One week after orchidectomy of NOD mice, circulating testosterone levels had fallen from 12 $\pm 2.1 \mathrm{ng} / \mathrm{ml}$ to $35.1 \pm 9.5 \mathrm{pg} / \mathrm{ml}(\mathrm{n}=12)$. At the same time, circulating estradiol did not fall significantly: 63 $\pm 13 \mathrm{pg} / \mathrm{ml}$ versus $46 \pm 10.5 \mathrm{pg} / \mathrm{ml}(\mathrm{n}=9)$. For diabetes incidence assessment, 15 mice were included in each group. Animals were considered diabetic when glycemia was higher than $11 \mathrm{mmol} / \mathrm{l}$ using Glukotest (BoehringerMannheim, Mannheim, Germany).

To assess the effect of castration on immunohistochemical parameters (islet size and infiltration with $\mathrm{CD}_{11 \mathrm{C}^{+}} \mathrm{DC}$ and lymphocytes), mice were used at 10 weeks of age (8/group). Unmanipulated NOD and NODscid females and males were also used at 5, 10, and 15 weeks of age for the measurement of islet size and $\mathrm{CD}_{11 \mathrm{C}^{+}} \mathrm{DC}$ infiltration (5 mice/group).

\section{Antibodies}

Islets were identified by guinea pig anti-insulin polyclonal antibody (Dako, Glostrup, Denmark), which was used diluted 1:250 in PBS with 0.1\% Tween-20 (Merck-Schuchardt, Hohenbrunn bei München, Germany) (PBS/Tween). Anti-insulin binding was detected with horse radish peroxidase (HRP)-conjugated rabbit-antiguinea pig immunoglobulins (Dako). N418, identifying CD11c ${ }^{+}$DC (18), was used as a hamsterantimouse hybridoma culture supernatant. N418 was detected with HRP-conjugated goat-antihamster immunoglobulins (Jackson ImmunoResearch Laboratories, Inc., West Grove, Pennsylvania). Lymphocyte infiltrates were identified morphologically by means of a nuclear fast red counterstaining (Fluka, Buchs, Switzerland).

\section{Immunohistochemistry}

Mice were killed by cervical dislocation after bleeding from the orbital sinus under ether anesthesia. Pancreata were removed, embedded in OCT compound (Sakura, Zoeterwoude, The Netherlands), and frozen in dry ice-chilled isopentane for immunohistochemical studies. Tissues were stored at $-80^{\circ} \mathrm{C}$ until immunohistochemistry was performed. Before sectioning, microscopic slides were coated with a solution of $0.1 \%$ gelatine $/ 0.01 \%$ chromium-alum. Pancreas cryostat sections of $6 \mu \mathrm{m}$ were prepared from central regions of the pancreas that included sufficient numbers of islets. Only one section of each pancreas was stained and measured to assure that an individual islet was not examined more than once. Sections were fixed for 2 minutes in $2 \%$ hexazotized pararosaniline (Sigma, St. Louis, Missouri) (De Jong et al, 1991). After a wash with PBS/Tween, slides were incubated with first-step monoclonal antibodies for 30 minutes at room temperature. Subsequently, slides were washed with PBS/Tween and incubated with second-step antibodies in the presence of $2 \%$ normal mouse serum for 30 minutes at room temperature. After an additional wash with PBS/Tween, slides were incubated with $0.05 \%$ (w/v) Ni-di-amino-benzidine (Ni-DAB) (Sigma) with $0.02 \% \mathrm{H}_{2} \mathrm{O}_{2}$ and washed in water after 3 minutes. Finally, slides were counterstained for 3 minutes in nuclear fast red, dehydrated in a graded ethanol series, and mounted. For each series of islet sections, one slide was stained with a second antibody only as a control for endogenous peroxidase activity and nonspecific binding of the second step. A section of spleen was included as a positive control.

\section{Quantification of Immunohistochemistry}

Total and marker-positive surface areas of infiltrated islets were assessed via a VIDAS-RT image analysis system (Kontron Elektronik GmbH/Carl Zeiss, Weesp, The Netherlands). Measurements were done at a magnification of $\times 100$. The results of the measurements were expressed in pixels. At a magnification of $\times 100$, the size of one pixel is $1.13 \times 10^{-6} \mathrm{~mm}^{2}$.

For the measurement of islet sizes, islets were identified by means of an anti-insulin staining. Only the endocrine cell contribution was measured; the immune cell contribution to islet area in mice with advanced insulitis is not counted. For the measurement of infiltration, islets, peri-islet areas, and lymphocyte infiltrates were recognized morphologically and encircled by the investigator. Figure 4 shows the definition of the islet area (I), the peri-islet area (P), and the lymphocyte infiltrate (L).

$\mathrm{CD}_{11 \mathrm{C}^{+}} \mathrm{DC}$ are present mainly in the peri-islet location, but also within the islet. Therefore, CD11c ${ }^{+}$ DC infiltration in the peri-islet and islet areas was measured and expressed relative to peri-islet- and islet-area size, respectively. For lymphocyte infiltrates, infiltrates were expressed as absolute infiltrate sizes in pixels, because lymphocytes are not yet infiltrating the islets at the age under investigation but rather form a cuff at the side of the islet. The size of this cuff is directly related to the number of lymphocytes present. Therefore, it is not necessary to express lymphocyte infiltration relative to islet size. Thus, DC infiltration is expressed in a relative manner, whereas lymphocyte infiltration is expressed absolutely.

For all measurements, the results were analyzed for the total number of islets in a given experimental group and not per individual mouse. The reason for this was that there was an extensive variability in the progression of the disease and therefore in the number of islets available for analysis prior to destruction. A mean of 170 islets was analyzed for every age-strain group of five to eight mice.

\section{Statistical Analysis}

The $\chi^{2}$-test was used to analyze differences in the prevalence of diabetes at 23 weeks of age between the orchidectomized mice and the sham-operated mice. Also, statistical comparison of the percentages of mega-islets in the two groups was carried out using the $\chi^{2}$-test. Statistical comparison of the amount of infiltration with $\mathrm{CD}_{11 \mathrm{c}^{+}} \mathrm{DC}$ and the amount of lym- 
phocyte infiltration between groups was carried out by the Mann-Whitney U-Wilcoxon rank sum W test. The level of significance was set at $p<0.05$.

\section{Acknowledgements}

The authors wish to thank M. Throsby for correction of the English manuscript, M. Calise and J. Coulaud for technical assistance, and T. v. Os for preparation of the figures.

\section{References}

Amrani A, Durant S, Throsby M, Coulaud J, Dardenne M, and Homo-Delarche F (1998). Glucose homeostasis in the nonobese diabetic mouse at the prediabetic stage. Endocrinology 139:1115-1124.

Ansar Ahmed S, Penhale WJ, and Talal N (1985). Sex hormones, immune responses, and autoimmune diseases. Mechanisms of sex hormone action. Am J Pathol 121:531551.

Bailey CJ and Ahmed-Sorour H (1980). Role of ovarian hormones in the long-term control of glucose homeostasis. Effects of insulin secretion. Diabetologia 19:475-481.

Basabe JC, Chieri RA, and Foglia VG (1969). Action of sex hormones on the insulinemia of castrated female rats. Proc Soc Exp Biol Med 130:1159-1161.

Beeson PB (1994). Age and sex associations of 40 autoimmune diseases. Am J Med 96:457-462.

Dahlen E, Dawe K, Ohlsson L, and Hedlund G (1998). Dendritic cells and macrophages are the first and major producers of TNF-alpha in pancreatic islets in the nonobese diabetic mouse. J Immunol 160:3585-3593.

De Jong JP, Voerman JS, Leenen PJ, Van der Sluijs-Gelling AJ, and Ploemacher RE (1991). Improved fixation of frozen lympho-haemopoietic tissue sections with hexazotized pararosaniline. Histochem J 23:392-401.

Doglioni C, Gambacorta M, Zamboni G, Coggi G, and Viale G (1990). Immunocytochemical localization of progesterone receptors in endocrine cells of the human pancreas. Am J Pathol 137:999-1005.

Fitzpatrick F, Lepault F, Homo-Delarche F, Bach JF, and Dardenne M (1991). Influence of castration, alone or combined with thymectomy, on the development of diabetes in the nonobese diabetic mouse. Endocrinology 129:13821390.

Fox HS (1992). Androgen treatment prevents diabetes in nonobese diabetic mice. J Exp Med 175:1409-1412.

Goillot E, Mutin M, and Touraine JL (1991). Sialadenitis in nonobese diabetic mice: Transfer into syngeneic healthy neonates by splenic T Iymphocytes. Clin Immunol Immunopathol 59:462-473.

Grossman CJ (1984). Regulation of the immune system by sex steroids. Endocr Rev 5:435-455.

Gu D, O'Reilly L, Molony L, Cooke A, and Sarvetnick N (1995). The role of infiltrating macrophages in islet destruction and regrowth in a transgenic model. J Autoimmun 8:483-492.

Hennebold JD and Daynes RA (1994). Regulation of macrophage dehydroepiandrosterone sulfate metabolism by inflammatory cytokines. Endocrinology 135:67-75.
Hoek A, Allaerts W, Leenen PJ, Schoemaker J, and Drexhage HA (1997). Dendritic cells and macrophages in the pituitary and the gonads. Evidence for their role in the fine regulation of the reproductive endocrine response. Eur $\mathrm{J}$ Endocrinol 136:8-24.

Homo-Delarche F (1997). Beta-cell behaviour during the prediabetic stage. Part II. Non-insulin-dependent and insulindependent diabetes mellitus. Diabetes Metab 23:473-505.

Homo-Delarche F and Boitard C (1996). Autoimmune diabetes: The role of the islets of Langerhans. Immunol Today 17:456-460.

Homo-Delarche F and Durant S (1994). Hormones, neurotransmitters and neuropeptides as modulators of lymphocyte functions. In: Rola-Pleszczynski M, editor. Immunopharmacology of lymphocytes. Handbook of immunopharmacology. London: Academic Press, 171-240.

Homo-Delarche F, Fitzpatrick F, Christeff N, Nunez EA, Bach JF, and Dardenne M (1991). Sex steroids, glucocorticoids, stress and autoimmunity. J Steroid Biochem Mol Biol 40: 619-637.

Houssay BA (1951). Action of sex hormones on experimental diabetes. Br Med J 2:505-510.

Hunger RE, Carnaud C, Vogt I, and Mueller C (1998). Male gonadal environment paradoxically promotes dacryoadenitis in nonobese diabetic mice. J Clin Invest 101:1300-1309.

Jansen A, Homo-Delarche F, Hooijkaas H, Leenen PJ, Dardenne M, and Drexhage HA (1994). Immunohistochemical characterization of monocytes-macrophages and dendritic cells involved in the initiation of the insulitis and beta-cell destruction in NOD mice. Diabetes 43:667-675.

Jansen A, Rosmalen JGM, Homo-Delarche F, Dardenne M, and Drexhage HA (1996). Effect of prophylactic insulin treatment on the number of ER-MP23+ macrophages in the pancreas of NOD mice. Is the prevention of diabetes based on beta-cell rest? J Autoimmun 9:341-348.

Kava RA, West DB, Lukasik VA, and Greenwood MR (1989). Sexual dimorphism of hyperglycemia and glucose tolerance in Wistar fatty rats. Diabetes 38:159-163.

Lavine RL, Chick WL, Like AA, and Makdisi TW (1971). Glucose tolerance and insulin secretion in neonatal and adult mice. Diabetes 20:134-139.

Leiter EH (1988). Control of spontaneous glucose intolerance, hyperinsulinemia, and islet hyperplasia in nonobese C3H.SW male mice by $\mathrm{Y}$-linked locus and adrenal gland. Metabolism 37:689-696.

Leiter EH (1989). The genetics of diabetes susceptibility in mice. FASEB J 3:2231-2241.

Lenzen S and Bailey CJ (1984). Thyroid hormones, gonadal and adrenocortical steroids and the function of the islets of Langerhans. Endocr Rev 5:411-434.

Pavlovic D, Chen MC, Bouwens L, Eizirik DL, and Pipeleers D (1999). Contribution of ductal cells to cytokine responses by human pancreatic islets. Diabetes 48:29-33.

Prochazka M, Gaskins HR, Shultz LD, and Leiter EH (1992). The nonobese diabetic scid mouse: Model for spontaneous thymomagenesis associated with immunodeficiency. Proc Natl Acad Sci USA 89:3290-3294. 
Renauld A, Sverdlik RC, Fels RC, von Lawzewitsch I, Perez RL, Foglia VG, and Rodriguez RR (1980). Metabolic and histological pancreatic changes induced by orchidectomy in dogs. Horm Metab Res 12:370-376.

Rosmalen JGM, Homo-Delarche F, Durant S, Kap M, Leenen PJM, and Drexhage HA (2000a). Islet abnormalities associated with an early influx of dendritic cells and macrophages in NOD and NODscid mice. Lab Invest 80:769-777.

Rosmalen JGM, Martin T, Dobbs C, Voerman JSA, Drexhage HA, Haskins K, and Leenen PJM (2000b). Subsets of macrophages and dendritic cells in nonobese diabetic mouse pancreatic inflammatory infiltrates: Correlation with the development of diabetes. Lab Invest 80:23-30.

Rossini AA, Williams RM, Appel MC, and Like AA (1978). Sex differences in the multiple-dose streptozotocin model of diabetes. Endocrinology 103:1518-1520.
Simons PJ, Delemarre FG, and Drexhage HA (1998). Antigenpresenting dendritic cells as regulators of the growth of thyrocytes: A role of interleukin-1beta and interleukin-6. Endocrinology 139:3148-3156.

Tesone M, Chazenbalk GD, Ballejos G, and Charreau EH (1979). Estrogen receptor in rat pancreatic islets. J Steroid Biochem 11:1309-1314.

Wilder RL (1995). Neuroendocrine-immune system interactions and autoimmunity. Annu Rev Immunol 13:307-338.

Winborn WB, Sheridan PJ, and McGill HC (1983). Estrogen receptors in the islets of Langerhans of baboons. Cell Tissue Res 230:219-223. 